\title{
SWTICH DE ESQUEMAS ANTIRRETROVIRAIS DURANTE A PANDEMIA DE COVID- 19 EM UM CENTRO DE REFERÊNCIA DA AMÉRICA LATINA
}

\author{
Dirce Inês Silva \\ FHEMIG/HEM \\ dirceines68@gmail.com \\ Isabela Estrela Santos \\ estrela.izabela@gmail.com \\ Jaqueline Xavier Oliveira \\ jackjoy201@hotmail.com
}

RESUMO

INTRODUÇÃO: O tratamento da infecção pelo vírus da imunodeficiência humana (HIV) é realizado por meio da terapia antirretroviral (TARV) e vem apresentando avanços importantes no decorrer dos anos. Ocorreu a introdução de novas drogas e classes que ampliaram de modo significativo as opções para o tratamento da infecção pelo HIV-I. Existem razões para a troca (Swtich) da TARV, são eles: manutenção da supressão viral, resistência, probabilidade de maior adesão ao tratamento, eventos adversos, interações medicamentosas ${ }^{(1)}$. Durante a pandemia de Covid-19 que vivenciamos desde março de 2020 no Brasil muitas dificuldades ocorreram nos serviços de saúde, principalmente para as pessoas que vivem com HIV como: acesso aos serviços, diagnóstico, tratamento e acompanhamento ${ }^{(2.3)}$. OBJETIVO: Avaliar a prevalência de trocas de esquemas em um centro de referência da América Latina no período de Janeiro de 2020 a 3I de Julho de 202I. METODOLOGIA: Realizamos um estudo transversal no período de 2020 a 202I, utilizando o sistema de informação: Sistema de Controle Logístico de Medicamentos (SICLOM) do Ministério da Saúde. Os dados foram analisados no Statistical Package for the Social

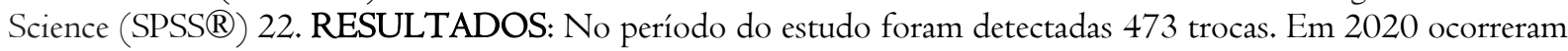
283 trocas, 83 em mulheres e 200 em homens. E 202I até o dia 3I/07/202I foram detectadas 190 trocas, 76 ocorreram em mulheres e II4 em homens. As trocas ocorreram devido: resistência, reações adversas, gestação, tratamento concomitante da tuberculose e simplificação do tratamento (Figura I e 2).

Figura I - Ocorências de Swtich de esquemas antirretrovirais

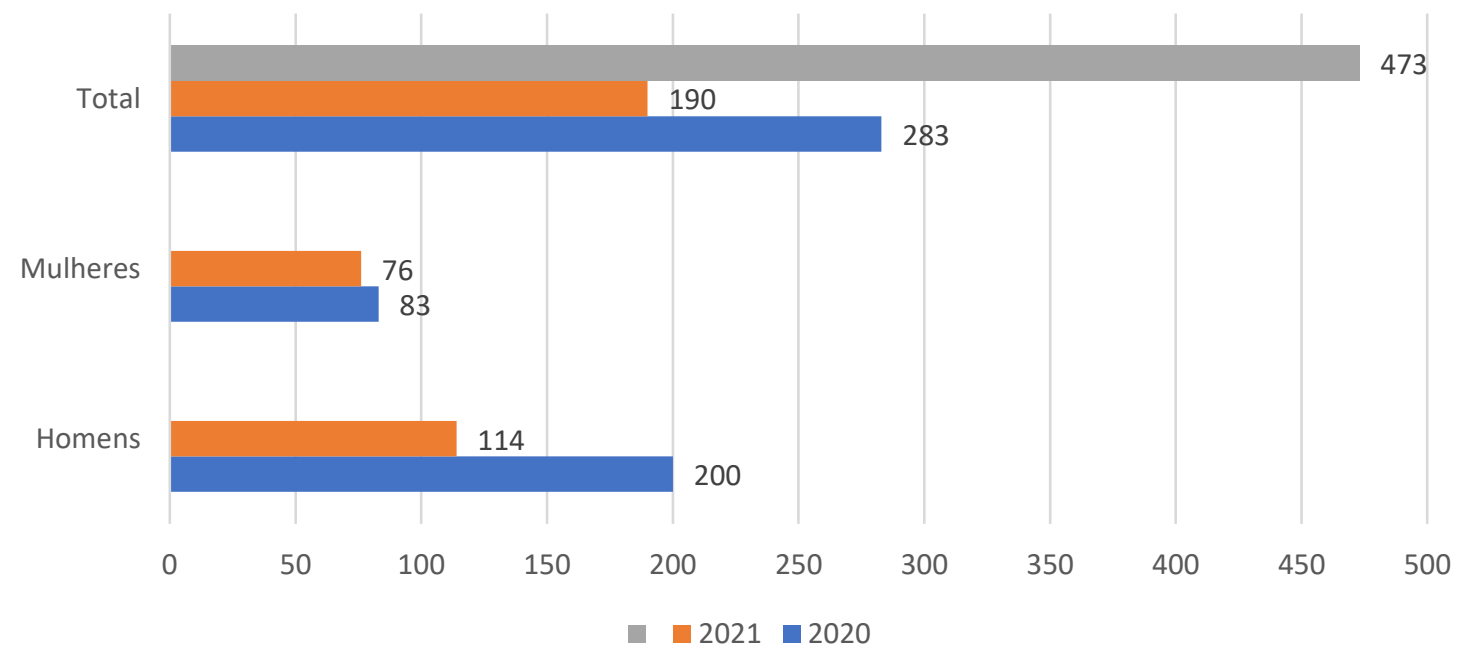


Figura 2- Razões de Trocas de Esquemas Antiretrovirais

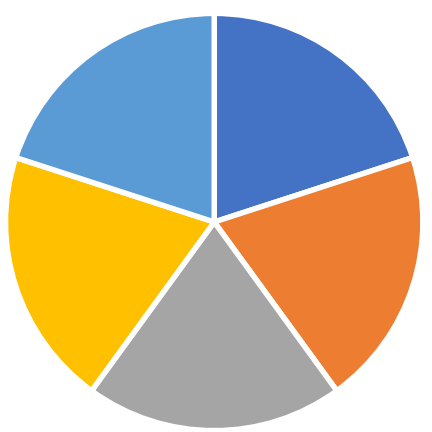

- Resistência - Reaçoes Adversas | Gestação | Tuberculose • Simplificação de Tratamento

CONCLUSÃO: Swtich dos esquemas antirretrovirais em utilização pode ser uma estratégia de simplificação da TARV, melhoria da adesão, e em muitos casos a redução de eventos adversos. $O$ arsenal terapêutico no contexto brasileiro é diversificado permitindo uma troca com segurança e sem risco de perda da eficácia virológica. Sendo uma estratégia para enfrentamento da infecção pelo HIV mesmo em tempos de pandemia do COVIDI9.

\section{REFERENNCIAS}

I-Brites, Carlos. Terapia antirretroviral atual: tendências e desafios. Estratégias de troca (switch) naterapia antirretroviral atual. Brazilian Journal of Infectious DiseaseVol 2. N ${ }^{\circ}$ I . Fevereiro 2016

2- Moura, Maria Lucia Costa de. (2020). Coronavírus e COVID-19. Revista Saúde Coletiva, 53, I0.

3- Parente, J. da S.; Azevedo, S. L. de .; Moreira, L. da F. A.; Abreu, L. M. .; Souza, L. V. de. The impact of social isolation on the COVID-I9 pandemic on access to HIV treatment and prevention services. Research, Society and Development, [S. 1.], v. IO, n. I, p. e28IIOIII692, 2021 